\title{
Thermo-physical Investigations of oils, N-(2-aminoethyl)- oleamide and Resulting Gels using TGA-DSC
}

\author{
NARENDRA S. JOSHI ${ }^{1,2}$, GOVINDA P. WAGHULDE ${ }^{2 * *}$ and GAURAV R. GUPTA ${ }^{3 *}$ \\ 'Department of Chemistry, Arts, Commerce \& Science College, Bodwad-425310, Maharashtra, India. \\ ${ }^{2}$ Department of Chemistry, D. D. N. Bhole College, Bhusawal-425201, Maharashtra, India. \\ ${ }^{3}$ Department of Chemistry, GTP College, Nandurbar-425412, Maharashtra, India. \\ *Corresponding author E-mail: grgupta83@gmail.com, drgpwaghulde@gmail.com
}

http://dx.doi.org/10.13005/ojc/370632

(Received: November 28, 2021; Accepted: December 30, 2021)

\section{ABSTRACT}

\begin{abstract}
Edible vegetable oils were gelled by using $\mathrm{N}$-(2-aminoethyl)-oleamide. Oils in their free state were subjected to differential scanning calorimetry (DSC) and thermogravimetric analysis (TGA) analysis. The gels of these oils were prepared by using $\mathrm{N}$-(2-aminoethyl)-oleamide as gelator and similar thermal analysis of the gels was carried out. The thermal analysis data obtained was used to determine specific heat capacity at constant pressure $\left(\mathrm{C}_{\mathrm{p}}\right)$. The values were compared with the reported values of heat capacities. It is observed that the thermal properties and transitions of oils and gels, specific heat capacity is helpful parameter to understand the fundamentals of gels and gelation strategies.
\end{abstract}

Keywords: Organo-gelator, Gelation, Heat capacity, Thermal analysis, TGA, DSC.

\section{INTRODUCTION}

The vegetable oils and fats are composed of different triacylglycerols (TAG), i.e., esters of fatty acids and glycerol. The chemical as well as physical properties of oils and fats are related to their fatty acid and triacylglycerol composition. ${ }^{1}$ In many food products, crystallization and melting behavior of the oils are important properties for functionality. These thermal properties are important for identification of vegetable oils and can be used in quantitative and qualitative ways. ${ }^{2-6}$ In confectionery, dairy and margarine industries, some of these vegetable fats like milk fat, hydrogenated fats, cocoa butter, etc. exhibits specific thermal behavior, relating to their useful properties in food formulations and their enormous use. It is necessary to know the physical properties, chemical composition and thermal behavior of the edible vegetable oils for a sufficient control of processes and for framing standard parameters for each desired use. ${ }^{7}$ The specific heat capacity at constant pressure $\left(C_{p}\right)$ can be considered as one of the important and useful physical properties. The information of the specific heat capacities of the oils is very useful to determine their behavior during different industrial processes.

This is an Open Access article licensed under a Creative Commons license: Attribution 4.0 International (CC- BY). Published by Oriental Scientific Publishing Company @ 2018 


\section{EXPERIMENTAL}

\section{Materials}

The oils viz., sesame oil, mustard oil, citriodora oil were purchased from local market. All the chemicals (extra pure) used for synthesis of gelator were purchased from Fisher Scientific.

\section{Instrumentation}

TGA-DSC analysis

The TGA-DSC analysis of the synthesized gelator was carried out at Central Instrumentation Facility, Shivaji University, Kolhapur and is reported in our previous communication. ${ }^{8}$

\section{Synthesis of gelator and the gels}

As reported in our earlier communication, several amide-based gelators were synthesized by using oleic acid as the precursor. Characterization of the synthesized gelator was done by using FTIR, ${ }^{1} \mathrm{H}-\mathrm{NMR},{ }^{13} \mathrm{C}-\mathrm{NMR}$ and Mass Spectral Analysis. A weighed quantity of the synthesized organo-gelators was added to the oil and the mixture was heated until all the gelator dissolves completely. The solution was then cooled to room temperature. Opaque gel forms slowly on cooling which was confirmed by inverting the tube. ${ }^{8}$

\section{RESULTS AND DISCUSSION}

Oils derived from wide variety of plants are an essential part of almost all the food products, and their structure related properties play a vital role in the production. The stat-of-the art exploration of these materials makes it essential to understand the complex structures and properties of these valuable materials. In addition to that, thermal analysis is the key tool in the arsenal of analytical chemistry for the elucidation of the structure related properties of these materials. ${ }^{9-10}$

Although, a systematic thermal analysis of variety of oils and food materials using TGADSC has already been reported very aptly in the literature and the results have been discussed very systematically. ${ }^{11-14}$ However, adequate reports have not been found on the detailed thermal analysis of the gels of oils, in particular the specific heat capacity measurements of such gel using thermal methods. In the following pages, thermal profiles of citriodora oil, mustard oil, sesame oil and their corresponding gels with $\mathrm{N}$-(2-aminoethyl)-oleamide have been discussed thoroughly.

Thermal analysis of Citriodora oil, N-(2aminoethyl)-oleamide and gel

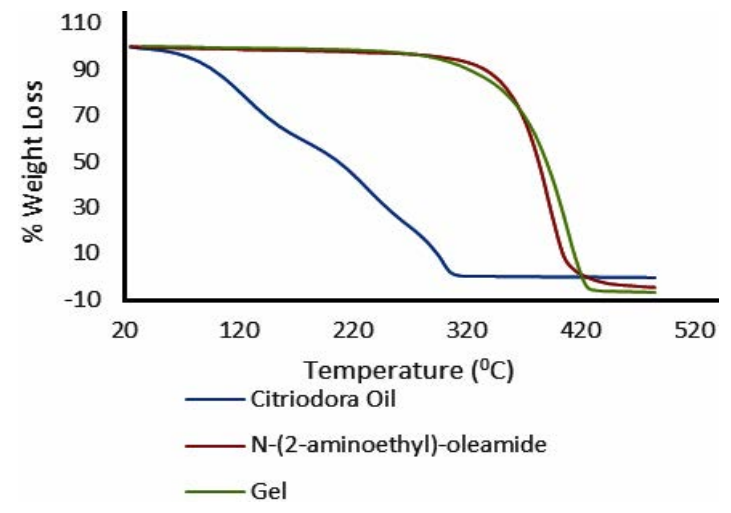

(1a)

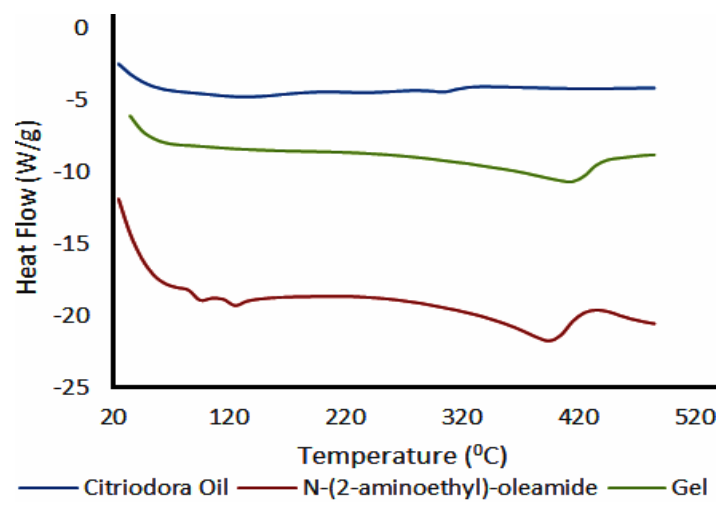

(1b)

Fig. 1. TGA-DSC analysis of citriodora oil, $\mathrm{N}$-(2-aminoethyl)-oleamide and gel

The closer scrutiny of the Fig. 1a, TGA of $\mathrm{N}$-(2-aminoethyl)-oleamide and gel reveals a very sharp single stage decomposition over $300^{\circ} \mathrm{C}$. The citriodora oil, a blend of triglycerides and free fatty acids, shows measurable pattern of decomposition as a function of temperature and possibly it is attributed to the composition and structural mesophasic changes occurred in such type of blends. ${ }^{1}$ In Fig. 1b, the heat flow response and the formation of endothermic pattern for citriodora oil, $\mathrm{N}$-(2-aminoethyl)-oleamide and their gel provides sound information about the smectic or mesophasic changes encountered in the oil and the gel. To our delight, it is to be observed that the resulting gel have transitory response between oil and gel.

Thermal analysis of Mustard oil, N-(2-aminoethyl)oleamide and gel 


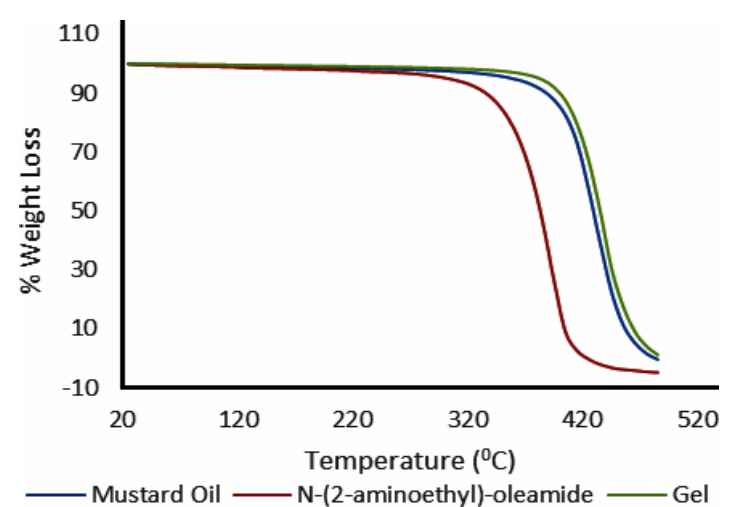

(2a)

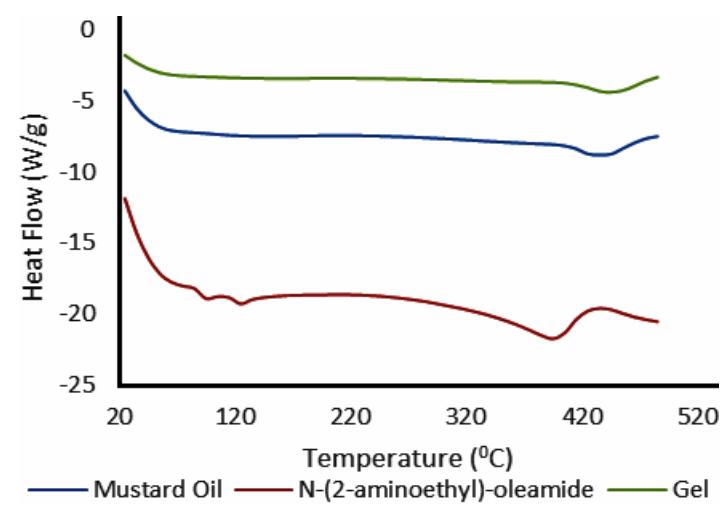

(2b)

Fig. 2. TGA-DSC analysis of mustard oil, $\mathrm{N}$-(2-aminoethyl)-oleamide and gel

The closer scrutiny of the Fig. 2a, TGA of mustard oil, $\mathrm{N}$-(2-aminoethyl)-oleamide and gel reveals a very sharp single stage decomposition over $300^{\circ} \mathrm{C}$. In Fig. $2 \mathrm{~b}$, the heat flow response and the formation of endothermic pattern for mustard oil, $\mathrm{N}$-(2-aminoethyl)-oleamide and their gel provides sound information about the smectic or mesophasic changes encountered in the oil and the gel.

As mentioned earlier, all oils are blend of triglycerides and free fatty acids, and exhibited measurable pattern of decomposition as a function of temperature and possibly it is attributed to the composition and the structural mesophasic changes occurred in such type of blends. ${ }^{1}$ It is to be noted that in case of mustard oil and its gel with $\mathrm{N}-(2-$ aminoethyl)-oleamide, interesting pattern of heat flow and endo-peaks have been observed in which the oil have a transitory response between gel and a gelator.

Thermal analysis of Sesame oil, N-(2-aminoethyl)oleamide and gel

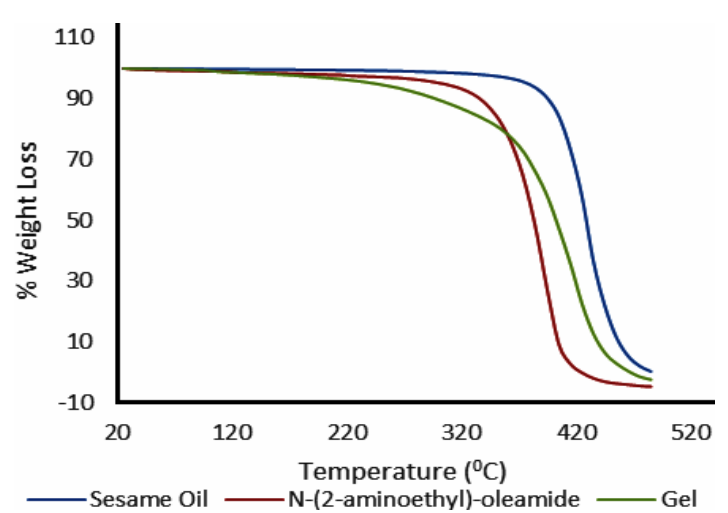

(3a)

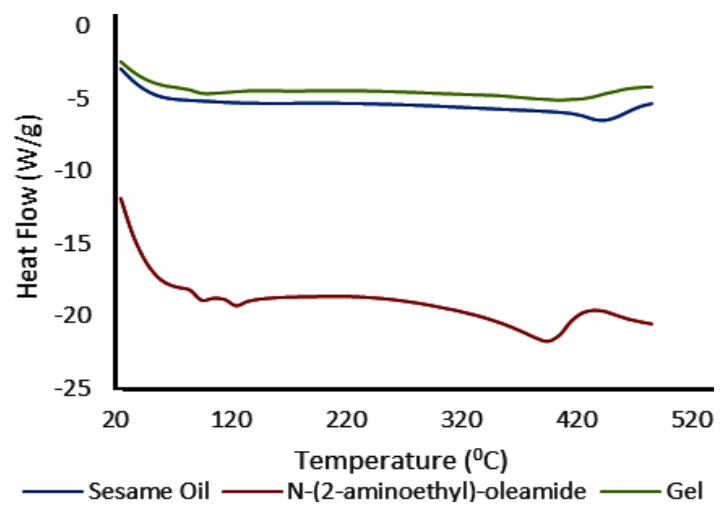

(3b)

Fig. 3. TGA-DSC analysis of sesame oil, $\mathrm{N}$-(2-aminoethyl)-oleamide and gel

The closer scrutiny of the Fig. $3 a$ and $3 b, T G A-D S C$ of sesame oil, $\mathrm{N}$-(2-aminoethyl)oleamide and gel reveals quite a similar pattern of decomposition as well as heat flow as a function of temperature with the previous mustard oil systems.

The utility of thermal methods towards the determination of thermal properties of oils or fats is one of the major areas of the application of thermal analysis (TGA-DSC). Till date, the thermal properties of quite a large number of oils and fats have extensively been studied using thermal methods like TGA and DSC. It is to note that the properties of oils and fats are intensely influenced by physio-chemical interactions, specifically among triglycerols (the fundamental species in oils and fats). The present literature also reveals that the physicochemical interactions present in the oils and the fats are very complicated, and a complete information and knowledge of their thermal properties requires a thorough examination of such interactions. As it is fact that we cannot have any first-hand information about the chemical composition of oils and fats 
based on these experiments. However, we can have a sound information about the science of the key thermodynamic changes that are associated with the phase transformation in the oil. Furthermore, these thermodynamic features are strongly depending on the general chemical composition of oils and fats and hence can be used for identification and full scope exploration of oils and fats, in qualitative and quantitative ways.

Thermal method (DSC) is particularly useful for studying the structure related interactions within the triglycerol components, because these techniques provide fundamental of the phase equilibrium diagrams for the studied systems, which provide a prowess of structure related information. It is also fact that beyond the compositional variation and their structure related interactions, the temperature-dependent polymorphic behavior of triglycerols in oils is responsible for their complicated thermal properties. On the other hand, DSC has advantage not only for thermodynamic analysis, but also for isothermal analysis of the system. Notably, the DSC profiles can also be explored towards the determination of one of the most important thermodynamic properties, i.e., specific heat capacity very systematically ${ }^{15-17}$. In the following pages, the specific heat capacity data for the studied systems are presented and discussed.

Specific heat capacity $\left(C_{p}\right)$ of Citriodora oil, N-(2aminoethyl)-oleamide and gel

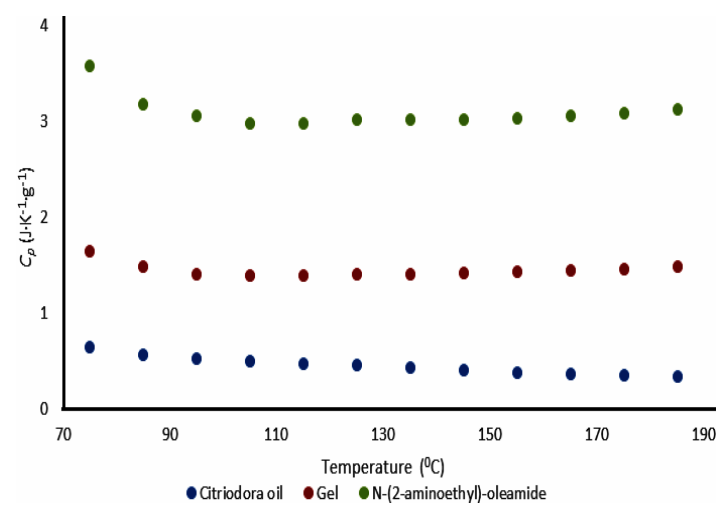

Fig. 4. Variation of specific heat capacity $\left(C_{p}\right)$ of citriodora oil, $\mathrm{N}$-(2-aminoethyl)-oleamide and gel as a function of temperature

From the Fig. 4, it is to be said that citriodora oil is the stable blend of triglycerols and have low specific heat capacity values than the corresponding gel.
Specific heat capacity $\left(C_{p}\right)$ of Mustard oil, $N-(2-$ aminoethyl)-oleamide and gel

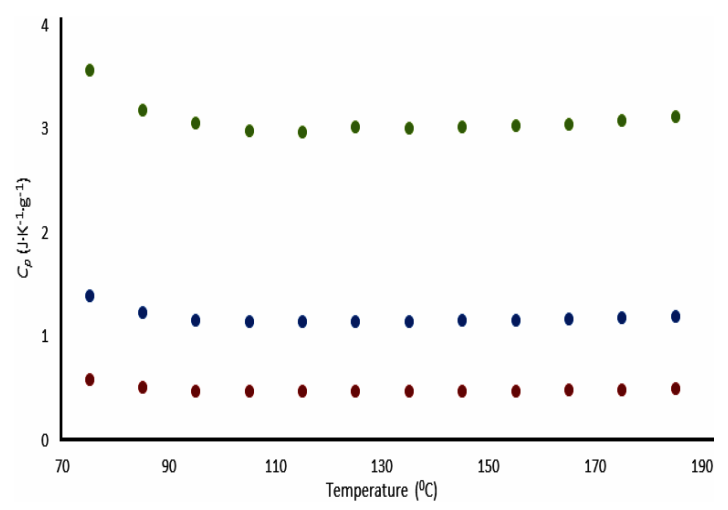

Fig. 5. Variation of specific heat capacity $\left(C_{p}\right)$ of mustard oil, $\mathrm{N}$-(2-aminoethyl)-oleamide and gel as a function of temperature

The closure scrutiny of Fig. 5 reveals that the gel of the mustard oil is quite stable as compared to the mustard oil.

Specific heat capacity $\left(C_{p}\right)$ of Sesame oil, N-(2aminoethyl)-oleamide and gel

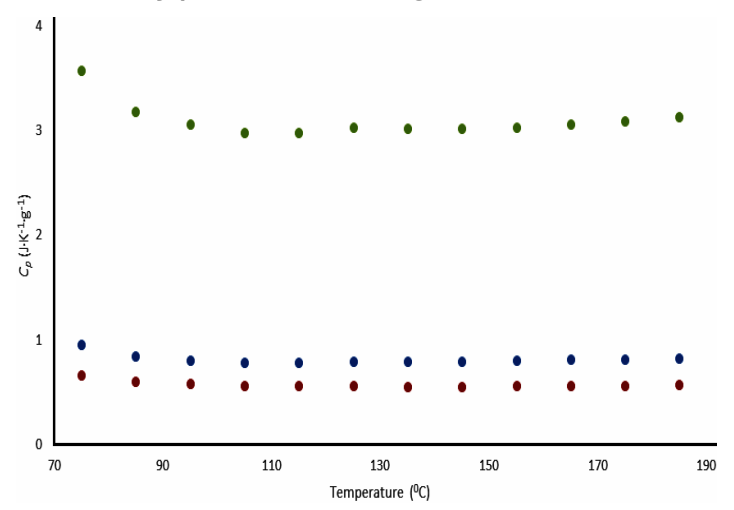

Fig. 6. Variation of specific heat capacity $\left(C_{p}\right)$ of sesame oil, $\mathrm{N}$-(2-aminoethyl)-oleamide and gel as a function of temperature

From the above Fig. 6 , it is to be said that the gel of sesame oil is comparatively stable than the corresponding gel.

As we know, DSC is one of the widely used instrumental techniques for determination of the structure related properties of oils and other biomaterials, and it is to be applied very aptly in the field of oils and fats to understand wide variety of complex reactions viz., phase transitions, crystallization and melting processes, and lipid oxidation in the oils. Notably, all the structure related changes in oils and fats involve endothermic or 
exo $\rightarrow$ thermic reactions. However, DSC is considered as a non $\neg$ specific analytical technique in order to measure the various structure related changes in oils and fats.

As specific heat capacity curves of the studied oils and their corresponding gels differ considerably, there is a basis for qualitative detection of adulteration or the presence of gelator from the perspectives of pure oils as noticed in the DSC curves (Fig. 1b, 2b, and 3b) as well as in specific heat capacity curves (Fig. 4-6). However, based on the characteristic composition, i.e., triglycerols of individual oils, the attempts have been made to comprehend the possible mechanism for the $\mathrm{H}$-bonding interactions between oil and the gelator (Scheme 1).

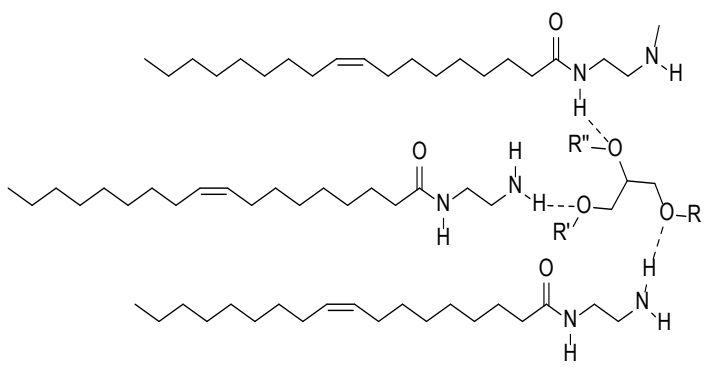

Scheme 1: Possible H-bonding interactions between triglycerol part of the oil and $\mathrm{N}$-(2-aminoethyl)-oleamide

\section{CONCLUSION}

The use of thermal analysis for understanding the gelation mechanism for the gel formation between oils and $\mathrm{N}$-(2-aminoethyl)oleamide on the basis of the chemical components is attempted here. The influence of triglycerols may find more information on further detailed investigation. Considering the huge global market in oils and gels, DSC could indeed be a useful technique for understanding thermal properties of oils and gels through characterization of the curves. In addition to that, new perspectives in the application of thermal methods to extract quality information about the studied systems are desirable. In the present study, it is found that the thermal properties and transitions of oils and gels, specific heat capacity is a benchmark parameter to understand the fundamentals of gels and gelation strategies. The DSC and thermal techniques are found to be very interesting for its application in food and related technology for academicians, researchers and industries in different sectors of food manufacture.

\section{ACKNOWLEDGEMENT}

We acknowledge the analytical services of CIF, Shivaji University, Kolhapur and the support from Dadasaheb Devidas Namdeo Bhole college, Bhusawal and Arts, Commerce and Science College, Bodwad for this work.

\section{Conflict of Interest}

The authors declare that we have no conflict of interest.

\section{REFERENCES}

1. Moretto, E.; Fett, R. Technologia de oleos e gorduras na industria de alimentos, Sao Paulo: Varela., 1998, 146.

2. Barkia, H.; Belkbir, L.; Jayaweera, S.A.A. J. Therm. Anal. Cal., 2003, 71, 97.

3. Turri, B. J. Therm. Anal. Cal., 2001, 66, 343.

4. Schaffer, B. J. Therm. Anal. Cal., 2001, 64, 659.

5. Gonzalez, C.; Rosa, J.M.; Fanega, M.A.; Lanz, J.; de Landaluce, S.O. J. Therm. Anal. Cal., 2002, 70, 263.

6. Ali, Z.; James, D.; O'Hare, W.T.; Rowel, F.J.; Scott, S. M. J. Therm. Anal. Cal., 2003, 71, 147.

7. Santos, J.C.O.; dos Santos, I.M.G.; de Souza, A.G.; Prasad, S.; dos Santos, A.V. J. Food Sci., 2002, 67, 1393-1398.

8. Joshi, N.S.; Waghulde, G.P.; Gupta, G.R.; Phalak, R.P. Orient. J. Chem., 2021, 37(5), 1109-1116.

9. Tan, C.P.; Che Man, Y.B. J. Am. Oil Chem.
Soc., 2000, 77(2), 143-155.

10. Almoselhy, R.I.M. Am. Res. J. Agri., 2020, 6(1), 1-9.

11. Gupta, G.R.; Shaikh, V.R.; Patil, K. J. Curr. Phy. Chem., 2018, 8(3), 175-185.

12. Tomar, P. A.; Yadav, S. M.; Jahagirdar, A. A.; Gupta, G. R. Catalysis in Green Chemistry and Engineering., 2020, 2, 133-141.

13. Gupta, G.R.; Shaikh, V.R.; Kalas, S.; Patil, K. J. Current Physical Chemistry., 2021, 11(1), 18-26.

14. Chiavaro, E. CRC Press, U.S.A., 2015.

15. Gupta,G.R.; Patil, P.D.; Shaikh,V.R.; Patil,K.J.; Kolhapurkar,R.R.; Dagade,D.H. Curr. Sci., 2018, 114(12), 2525-2529.

16. Patil, K.S.; Zope, P.H.; Patil, U.T.; Patil, P.D.; Dubey, R.S.; Gupta, G.R. Bull. Mater. Sci., 2019, 1-9.

17. Tomar, P.A.; Yadav, S.M.; Gupta, G.R. Polym. Bull., 2014, 1349-1358. 